This item was submitted to Loughborough's Research Repository by the author.

Items in Figshare are protected by copyright, with all rights reserved, unless otherwise indicated.

\title{
Energyscapes: linking the energy system and ecosystem services in real landscapes
}

PLEASE CITE THE PUBLISHED VERSION

http://dx.doi.org/10.1016/j.biombioe.2012.05.025

PUBLISHER

(C) Elsevier

VERSION

SMUR (Submitted Manuscript Under Review)

LICENCE

CC BY-NC-ND 4.0

\section{REPOSITORY RECORD}

Howard, David C., Paul J. Burgess, Simon J. Butler, Steve J. Carver, Timothy Cockerill, Alastor M. Coleby, Guohui Gan, et al.. 2019. "Energyscapes: Linking the Energy System and Ecosystem Services in Real Landscapes". figshare. https://hdl.handle.net/2134/9767. 
This item was submitted to Loughborough's Institutional Repository (https://dspace.lboro.ac.uk/) by the author and is made available under the following Creative Commons Licence conditions.

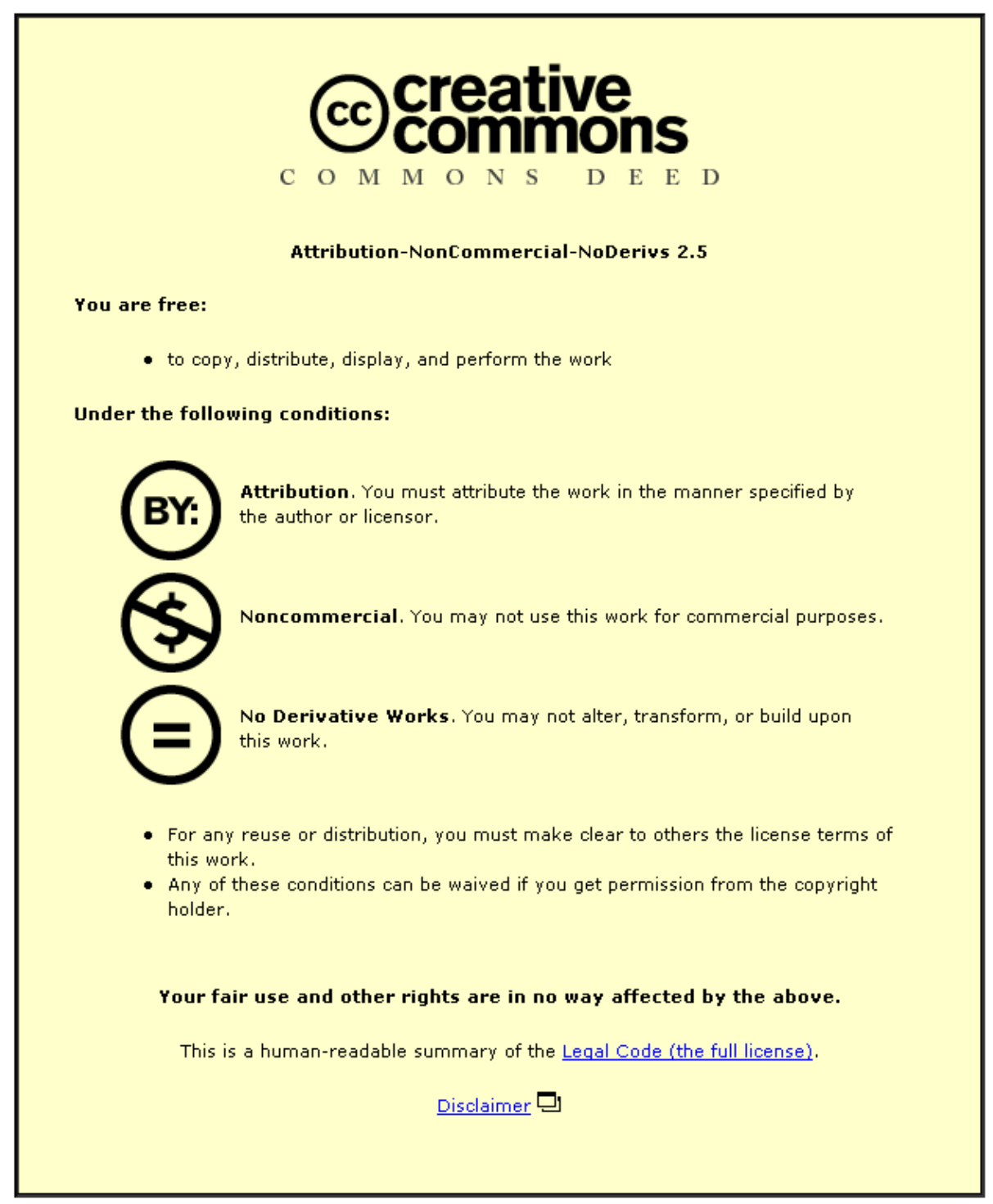

For the full text of this licence, please go to: http://creativecommons.org/licenses/by-nc-nd/2.5/ 
Elsevier Editorial System(tm) for Biomass and Bioenergy Manuscript Draft

Manuscript Number: JBB-D-11-01143R1

Title: Energyscapes: linking the energy system and ecosystem services in real landscapes

Article Type: Special Issue:Energy landscape(REBECa)

Keywords: energyscape, ecosystem services, energy system, Britain, Marston Vale

Corresponding Author: Dr David Howard,

Corresponding Author's Institution: Centre for Ecology \& Hydrology

First Author: David C Howard

Order of Authors: David C Howard; Paul J Burgess; Simon J Butler; Steve J Carver; Timothy Cockerill; Alastor M Coleby; Guohui Gan; Chris I Goodier; Dan van der Horst; Klaus Hubacek; Richard Lord; Andrew Mead; Monica Rivas-Casado; Richard A Wadsworth; Paul Scholefield

Abstract: The drive for sustainable energy production is leading to increased deployment of land based renewables. Although there is public support, in principle, for renewable energy at a national level, major resistance to renewable energy technologies often occurs at a local level. Within this context, it can be useful to consider the "energyscape" which we initially define as the complex spatial and temporal combination of the supply, demand and infrastructure for energy within a landscape. By starting with a consideration of the energyscape, we can then consider the positive and negative interactions with other ecosystem services within a particular landscape. This requires a multidisciplinary systems-approach that uses existing knowledge of landscapes, energy options, and the different perspectives of stakeholders. The approach is examined in relation to pilot case-study comprising a $155 \mathrm{~km} 2$ catchment in Bedfordshire, England. 
Energyscapes Highlights

- Novel approach setting the whole energy system in a real landscape context.

- Describes a method that can be used to clarify how different groups view biomass deployment

- Uses different stakeholders perspectives of how the landscape interacts with all ecosystem services and how modifications of the energy system will influence them.

- Demonstrated for Marston Vale, a sub catchment of the Great Ouse in eastern England.

- Applicable across spatial scales and geographic zones. 
1 Energyscapes: linking the energy system and ecosystem services in real landscapes

2 Howard, D.C. ${ }^{1}$, Burgess, P.J. ${ }^{2}$, Butler, S.J. ${ }^{3}$, Carver, S.J. ${ }^{4}$, Cockerill, T. ${ }^{5}$, Coleby, A.M. ${ }^{6}$, Gan, G. ,

3 Goodier, C.J. ${ }^{8}$, van der Horst, D. ${ }^{9}$, Hubacek, K. ${ }^{10}$, Lord, R. ${ }^{11}$, Mead, A. ${ }^{11}$, Rivas-Casado, ${ }^{2}{ }^{2}$,

4 Wadsworth, R.A. ${ }^{1}$ and Scholefield, P. ${ }^{1}$

$5{ }^{1}{ }^{*}$ Centre for Ecology \& Hydrology, Lancaster Environment Centre, Lancaster, LA1 4AP UK,

$6 \quad{ }^{2}$ School of Applied Sciences, Cranfield University, Cranfield, Bedfordshire, MK43 OAL UK

$7 \quad{ }^{3}$ School of Biological Sciences, University of East Anglia, Norwich, NR4 7TJ UK

$8 \quad{ }^{4}$ School of Geography, University of Leeds, Leeds LS2 9JT, UK

$9{ }^{5}$ Centre for Environmental Policy, Imperial College London, South Kensington Campus, London

10 SW7 2AZ, UK

$11{ }^{6}$ School of Earth and Environment, University of Leeds, Leeds, LS2 9JT, UK

$12{ }^{7}$ Faculty of Engineering, University of Nottingham, University Park, Nottingham, NG7 2RD, UK

$13{ }^{8}$ Department of Civil and Building Engineering, Loughborough University, Loughborough, LE11

14 3TU, UK

$15{ }^{9}$ School of Geography, Earth \& Environmental Science, University of Birmingham, Birmingham B15

16 2TT, UK

$17{ }^{10}$ Department of Geographical Sciences, University of Maryland, College Park, MD 20742, USA

$18{ }^{11}$ Department of Civil \& Environmental Engineering, University of Strathclyde, Glasgow,

19 G4 ONG UK

$20 \quad{ }^{11}$ Life Sciences, University of Warwick, Wellesbourne, Warwick, CV35 9EF, UK

$21 *$ Corresponding author

22 Centre for Ecology \& Hydrology

23 Lancaster Environment Centre

24 Library Avenue,

25 Bailrigg,

26 Lancaster

27 LA1 4AP

28 United Kingdom

29 Telephone: + $44(0) 1524595831$

30 FAX: +44 (0)1524 61536

31 e-mail: dhoward@ceh.ac.uk 
32 Abstract

33 The drive for sustainable energy production is leading to increased deployment of land based

34 renewables. Although there is public support, in principle, for renewable energy at a national level,

35 major resistance to renewable energy technologies often occurs at a local level. Within this context, it

36 can be useful to consider the "energyscape" which we initially define as the complex spatial and

37 temporal combination of the supply, demand and infrastructure for energy within a landscape. By

38 starting with a consideration of the energyscape, we can then consider the positive and negative

39 interactions with other ecosystem services within a particular landscape. This requires a multi-

40 disciplinary systems-approach that uses existing knowledge of landscapes, energy options, and the

41 different perspectives of stakeholders. The approach is examined in relation to pilot case-study

42 comprising a $155 \mathrm{~km} 2$ catchment in Bedfordshire, England.

43 Keywords: energyscape, ecosystem services, energy system, Britain, Marston Vale 


\section{Introduction}

Human use of energy is the major driver of anthropogenic climate change and challenges our ability to live sustainably [1] and [2]. However energy and climate change are not the only issues that determine sustainability, as we must also maintain and ideally enhance the ecological and social systems on which we depend. The benefits (and dis-benefits) that we gain from ecological systems are termed ecosystem services [3], [4], [5] and [6] and wise stewardship of the Earth requires us to understand how changes in energy demand, production and supply affect such services. For some ecosystem services, such as the provision of food, the interactions can be examined using established spatial models. By contrast it has proved to be less easy to quantify the impact on the cultural services within a given area, and it is often these issues that form the focus of objections to renewable energy development.

The need for a low carbon energy system is seen as an essential part of the solution to anthropogenic climate change and is recognized by Governments (e.g. [7]). However, there is growing recognition that the deployment of low carbon energy technologies may have substantial impacts on a range of ecosystem services in the locality where they are deployed [8]. Most land based renewables (LBR), including bioenergy, have a lower energy content than fossil fuels and consequently have much larger spatial footprints. This need for increased land area and more efficient use has led to a growing interest in more distributed approaches to energy production and distribution as a way to reduce carbon emissions [9]. In addition human population growth and increasing per capita consumption places further demands on land to provide food, fiber, and potable water; space for accommodation, occupation and recreation; and conservation of natural and social heritage. Modification of any of these services may compromise the delivery of others and the risk of such trade-offs must be recognized if conflicts between policies and goals are to be avoided.

New tools are needed to allow us to understand how changes to our energy system (both large and small) interact with ecosystem services, both in terms of technical assessments and in terms of planning decisions [10]. The standard approach for assessment involves planning applications and environmental impact assessments that narrowly focus on selected elements and exclude other 
important features. The situation is exacerbated by the potential deployment of different combinations and scales of renewable energy technologies in different localities. In these circumstances, the largely unknown synergies and conflicts generated by the technologies may well produce outcomes different from the sum of their individual effects.

As the provision of energy becomes decentralized the issues become more location and site-specific; it will become increasingly important to consider energy demand, production and supply in a more local area or landscape context. Decision makers are faced with the challenge of developing systems which will allow local sources of energy to be incorporated with currently centralized supplies. There is currently uncertainty regarding the stability and temporal dynamics of the interactions between different renewable technologies and local energy demand, this is complicated by the historical legacy and the infrastructure needed to deliver the energy generated. Some of this uncertainty is associated with the relatively poor availability of data with which to investigate local spatial interactions consistently across regional or national scales. Perhaps surprisingly, even nationally available basic resource data are often insufficiently detailed to reliably identify technically optimal locations for smaller scale renewable energy installations, let alone support analysis of more subtle issues (e.g. [11]). The widespread acceptance of the incompatibility of datasets and modeling across scales also creates a schism between local and national planning.

The difficulty of understanding the impact of changes to the energy system is further compounded by our limited understanding of how it affects the provision of ecosystem services at a range of scales, from local to national and global. Each environmental function is potentially affected by changes to land management and the exploitation of associated ecosystem services; their response may be immediate or show delay and variation over time making the system impossible to model accurately. While there is plenty of research devoted to developing approaches for the technical and economic optimization of distributed generation systems (e.g. [12] and [13]), taking the perspective of the whole system is rare [14]. Ecosystem services and their social effects, have been largely neglected $[15]$ and where they have been examined they are usually considered at the national or larger scales, rarely considering local impacts, interactions and multiple effects [16]. Where environmental 
considerations are taken into account, these are largely constrained to direct impacts such as atmospheric carbon emissions (e.g.[17] and [18]). Our understanding of how to deploy energy production technologies to minimize negative local impacts and maximize energy benefits is usually incomplete and inconsistent. In fact, there is generally a disconnect in our understanding of actions and impacts elsewhere.

From the problems described above, it is clear that we do not currently have sufficient understanding of the processes and complexity in the real world to effectively forecast the impacts of changes to the energy system. Here we propose an alternative method of viewing the system, which provides the broader, whole system perspective that is needed for energy planning. It recognizes the importance of different spatial scales and uses scenario studies to explore with stakeholders the desirability and feasibility of particular local or regional interventions into the energy system. The approach requires a change in paradigm for most energy researchers who take a strictly scientific reductionist view. We recognize that this cannot be achieved rapidly, but in this paper we present a framework that will enable and encourage new spatial models, theories and datasets to be developed, accessed and used interchangeably (what is known as 'plug and play'). It also allows existing national land use databases such as the Countryside Survey [19] to be used to assist interpretation across scales and targeting of resources to maximize the returns from existing data.

Most traditional modeling of the energy system employs an additive approach, concentrating on energy sources. These are each examined and then their outputs summed; the calculations are usually aspatial, taking no account of the geographic distribution of material, let alone any interactions. Even where demand is included (e.g. [20]) geography and interactions are ignored. Efforts have been made to link such energy production models to a spatial infrastructure (e.g. [21]), but not the whole system. These models serve a valuable purpose in providing a crude estimate of overall potential, but they are impossible to interpret for local environmental impacts [22] and are imperfect for assessment in the context of productivity in the wider economy. Our long term vision is to develop a flexible spatiotemporal analysis framework in which the impacts of changes in energy system configurations can be identified for any specified area. The consequences of the change will be judged by a comprehensive 
range of environmental and socio-technical indicators. The framework will need to represent (i)

127 actual and potential energy sources, (ii) energy transportation pathways, (iii) the energy demand

128 across a local area and (iv) be capable of seamlessly linking to examinations of other ecosystem goods

129 and services. Taken in its entirety, we call this the "energyscape" of the local area (a term first used

130 with this breadth by Louise Heathwaite [23]). Combining such a framework with, for example,

131 models of ecosystem behavior could provide a new means to facilitate "what-if" comparisons of

132 alternative approaches to distributed generation. Ultimately it might be possible to highlight the trade-

133 offs between different scenarios and, with recognition of the different value judgments and interests

134 associated with different stakeholders, reduce land use conflicts. Optimal energy solutions combining

135 the technical elements of the energy landscape should not only minimize their wider impact but also

136 be set in the context of sustainability.

137 Our project involved a one year pilot study to discover the potential benefits and obstacles in using a whole system approach to evaluate the energy system. Our aim was to determine how an

139 understanding of the energyscape and ecosystem services could help guide the deployment of LBR.

140 To deliver this we examined energy system options in the context of the wider landscape by taking

141 into consideration the interactions both between the energy components and ecosystem services. We

142 are seeking to use it both as a proof of concept and a test bed in which we can identify the techniques

143 needed, beneficiaries and differences to the current reductionist approaches; a major deliverable for

144 the future will be a generic system that will advance evidence based sustainable development.

145 In this paper we propose a new approach incorporating the whole landscape in terms of structure and

146 process viewed from an energy perspective that can help surmount the problems of the complex

147 dynamic system described above. We will describe the components of our project that demonstrate

148 how to collect evidence for better planning, take account of different people's perspectives and

149 prepare for dramatic changes in land use.

$150 \quad$ 2. Materials and Methods

$151 \quad 2.1$ Defining the energyscape 
152 Although the term "energyscape" was used in New Zealand for a project (started in 2007) which

153 developed long range assessments of national energy flows [24], there is, to our knowledge, no formal

154 definition of an "energyscape". As a term, energyscapes sounds familiar and people intuitively make their own definition, but our first goal was to formalize a succinct, explicit definition. As a large interdisciplinary team of natural and social scientists we discussed (at length) and eventually agreed on a working definition of an energyscape as "the complex spatial and temporal combination of the supply, demand and infrastructure for energy within a landscape". To ensure that this definition was both comprehensive and complete we contributed and commented on ideas on a wiki on the World Wide Web. The discussion focused on both the definition and the characteristics of an energyscape.

\subsection{Case study}

The second part of this paper briefly describes the application of an energyscapes framework for a case study area. The selected case study site, covering $155 \mathrm{~km} 2$, was Marston Vale (Figure 1), a subcatchment of the Great Ouse river in Bedfordshire, United Kingdom (UK). The land use, including currently consented development, is reasonably typical of lowland England being $69 \%$ agricultural land, $12 \%$ urban, $8 \%$ woodland and $11 \%$ other including water and landfill [25]. The population density is predicted to increase to a level (3.1 people per ha), which is between the density for England (3.9 people per ha) and the UK (2.5 people per ha). A full description of the site and the methodology is provided by Burgess et al [26], but the key issues are mentioned here for clarity. As a demonstration of the application of the energyscapes concept in Marston Vale, a GIS was constructed using ArcGIS [27]. Datasets describing a broad range of environmental characteristics (e.g. soil, climate, geology, topography) and land cover (using aerial photographs, Land Cover Map 2007 and field survey) were collated so that the existing functions of Marston Vale could be assessed. The functions were examined through the application of different models for production of both energy (e.g. biomass, wind, solar, ground-source heat, and landfill biogas) and other goods and services (such as food) [28]. These were then examined under different scenarios developed, in part, from the feedback from stakeholder workshops.

\subsection{Stakeholder perceptions of energy-ecosystem services interactions}


This section of the paper briefly outlines a method to improve our understanding of the perspectives

180 of different stakeholders on how change in the energy system will impact their local area. A two tier approach was developed. Firstly each individual was asked to identify the ecosystem services that they think are delivered by specific habitats. The dominant habitats were identified using Broad Habitats [29], as mapped in Land Cover Map 2007 (Figure 1).

\section{Figure 1 about here}

The information was collected by asking a series of questions that covered the breadth of ecosystem services with responses that range from strong agreement to strong disagreement. The approach and analysis [30] was then extended in a second questionnaire to identify how people viewed the sensitivity of different services to components of the renewable energy system. This was summarized to represent the opinions of different stakeholders and help clarify the reasons for their support, indifference or ambivalence. The Broad Habitats are a practical categorization of land into different types devised following the Rio Convention for Biological Diversity [31] that can be mapped locally. They provide a comprehensive coverage of all UK land and habitats against which those requiring special protection or management can be viewed and are used by both conservation agencies and Government to assess targets. As the spatial footprint of the energy system changes, it can be expressed in units such as Broad Habitats so that the conflict with conservation policies can be identified.

\section{Results}

\subsection{Exploration of a concept}

Our initial definition of an energyscape was "the complex spatial and temporal combination of the supply, demand and infrastructure for energy within a landscape". A further exploration of the term focused on two components: the form and function of an energyscape (Table 1). Some of the definitions included no consideration of energy demand. There was also a debate on the extent to which "ecosystem services" were best considered as "separate from" or as "part of the energyscape". 
204 One pertinent comment from a local stakeholder meeting was "why are you inventing a new term:

205 why do you not simply refer to an energy landscape?"

\section{Insert Table 1 about here}

207 Most of the definitions recognize that an energyscape has both a geographic extent and a timeframe that reflect its evolution, development and potential. Although the definitions do not cite a specific spatial scale, there are probably benefits to choosing a scale where the area has a functional identity.

210 For example, for the case study area, a locally-recognized sub-catchment was chosen. Whilst it is not

211 essential to use natural divisions of a landscape, a catchment's boundaries reflect breaks and shifts in

212 natural processes and the viewshed associated with a catchment often creates a unit that can be

213 identified by people.

214 Although the spatial scale should represent a functional unit, it is recognized that any studied area will

215 not be a closed system but it will have inputs and outputs of energy and ecosystem services across the

216 boundary (Figure 2). Equally, the boundary may not be a crisp border as shown in Figure 1; some

217 parts may have a recognizable border, for example the M1 defining the south western border, but in

218 other places the definition is fuzzy. This vagueness does not devalue the region to different local

219 stakeholders but merely qualifies their considerations.

220 No single, pithy final definition was unanimously agreed on; our original definition was not

221 compromised by any of the suggestions which are not mutually exclusive. An energyscape definitely has a spatial and temporal basis and focuses on both internal interactions between the energy system components (demand, supply and delivery) and interactions with other components of real landscapes such as people, structures, topography and ecosystem services.

Figure 2 about here

226 Energy may be produced, transmitted, stored and/or used by components of the energyscape within the system boundary and only one of these elements is needed for the energy to be viewed as part of the system. For example, we would argue that even if energy simply passes through the energyscape through a high tension electricity network it should be included. 
230 As the definition describes a complex dynamic system, when considering future options, potential

231 features of the energyscape not present at the time of observation should be included; the

232 classification of components and methods of linking (co-registering) data are key to this process. For

233 example, at the time of writing our case study area includes no energy from waste installations, but

234 they are being actively considered. It is only through a systematic approach that consideration of the

235 possible energy options (Table 2), and the key ecosystem services in an area (Table 3) will be encouraged. Early involvement of a wide range of stakeholders is key to the process as their perceptions of what is important and which ecosystem services matter to them provides important guidance for development of scenarios, data gathering and planning of locations for LBR.

Insert Table 2 about here

\subsection{Inter-relationships with ecosystem services}

241 Ultimately any energyscape forms part of the wider biosphere, the self-regulating system containing

242 all ecosystems that overlaps the lithosphere, hydrosphere and atmosphere creating a zone that

243 supports life (Figure 3). The addition of solar and cosmic radiation generates the systems of climate,

244 terrain, soil/geology, hydrology and ecology that we exploit to support our life.

Figure 3 about here

246 Ecosystem services are defined as the products and services that people derive from ecological

247 systems. The Millennium Ecosystem Assessment [32] classified these services into four groups

248 provisioning, regulation, supporting and cultural. In addition to these, shown to the left in Figure 2

249 de Groot and others also highlight the carrier and habitat services as shown on the right [33] and [34].

250 Costanza and others have proposed additional characterizations as indicated in the box to the lower

251 right [35]. Such categorizations are useful to ensure that we consider the full range of benefits that we gain from our environment.

253 The energy infrastructure physically ties energy components to the landscape. Energy sources, energy

254 demand and energy delivery systems potentially interact with most if not all ecosystem services; they may also be explicit services (e.g. provision of energy) or implicitly embedded (e.g. regulation of 
greenhouse gases) in specific categories. It is important not only to ensure that the key parts of the energy system are considered, but how they differentially interact with different ecosystem services through their physical location.

\subsection{Case study}

Within this paper only a brief indication of the outputs from the case study analysis has been presented by way of a demonstration of the potential of this approach. Detailed results and analysis are given by Burgess et al [26], Armitage et al.[28] and Wadsworth et al. [30]. As described earlier, Marston Vale is a lowland predominantly agricultural landscape which currently offers provisioning of human food, animal feed, and fiber. The existing land use was described through field survey and remote sensing and the production through the key provisioning ecosystem services was modeled (Figure 4).

\section{Figure 4 about here}

Other ecosystem services that were assessed include the regulation of biochemical processes (e.g. soil carbon), culture (e.g. recreation) and conservation (provision of appropriate and sufficient habitats for farmland birds). The local energy demand was also mapped (Figure 5) and, although simple spatial overlay is not appropriate, this information is extremely useful in identifying the hot spots for service that can be used to improve efficiency by matching to local generation. The information is also valuable for validation and informing stakeholders about their regional energy self-sufficiency and thus can provide an educational service.

\section{Figures 5 about here}

276 The implications of expanding bioenergy provision were considered in a number of ways. One set of scenarios examined the deployment of different products from food or fiber into energy and fuel, leaving the landscape effectively unchanged. A second set of scenarios examined the conversion of land currently used for agricultural production in specific locations within Marston Vale to energy crop production and alternative forms of renewable energy, to meet a number of government-defined targets for meeting energy demand. 
283 The scenario outputs helped not only to inform and engage local stakeholders but also to elicit new information about strategies and plans that are being developed. Different groups of stakeholders were asked to respond to the questions relating the area's common Broad Habitats (Arable and horticultural, Improved grass. Neutral grass, Broadleaved, mixed and yew woodland, Standing open water, Rivers \& stream, Boundaries and linear features and Urban \& built up) to ecosystem services and then questioned about their opinion of the sensitivity to different changes in the energy system [30]. They were asked to score which ecosystem services were delivered by which Habitats using the questions in Table 3. The first analysis highlights the relative position of different stakeholders and suggests where issues may cause friction and where there are similar beliefs. They are then asked to score the impact of LBR options against the Broad Habitats suggesting if they consider them to be beneficial or damaging.

Table 4 provides an example of the output for one stakeholder's responses to questions of wind and biomass for Marston Vale. The table shows the sum of the scores representing the stakeholder's perception of threats $(-2,-1)$ or benefits $(1,2)$ of new LBR development in different habitats and on ecosystem services. The results suggest that the stakeholder has a number of concerns over wind turbines seeing negative impacts with services delivered by a number of habitats. There is special concern about the impact turbines would have on the regulating services provided by Deciduous, mixed and yew woodland; it is only the Urban and built up habitats where he/she sees benefits. In contrast, the options for bioenergy do not raise as many concerns for this individual. Only Boundaries and linear features have a net negative score, the impact being from the cultural services; cultural services appear to be the major cause for concern in biomass planting, with supporting services benefiting and the others showing a balance. The analyses presented back to the stakeholder provided scope for discussion and validation; they helped clarify an individual's position and allowed dialogue to begin to understand concerns and express them to others.

\section{Discussion}


Bringing together an understanding of the energy system and ecosystem services is a complex task.

309 Ecosystem services are often viewed as spatial processes that can be categorized through their

310 delivery by specific habitats that are geographically fixed. Conversely, the energy system is

311 commonly viewed as aspatial and identified in units ranging from household to national, but ignoring

312 their location or geographic characteristics. The process of describing an energyscape can help, in

313 part, to address this by modeling energy demand, supply and flows through real landscapes, thereby

314 helping to identify links, obstacles and important associations.

315 In this context the energyscape provides a representative framework containing geographic and spatial

316 characteristics; it does not necessarily have to be a complex simulation model. The individual

317 elements of an energyscape can be land parcels, each of which can have its own energy flow (Figure

318 6), that can be joined together to describe even larger energyscapes. This description suggests that the

319 approach is bottom up and requires masses of detailed data and intensive analysis, but this need not be

320 the case. Targeted and representative sampling as used by opinion polls and the Countryside Survey

321 and hybrid models of the style used to combine input output statistics with life cycle analysis (e.g.

322 [36]) can improve the efficiency and improve the consistency across scales.

\section{Insert Figure 6 about here}

The term "energyscape" was new to stakeholders associated with the project. As already indicated one respondent questioned the need for a new term, when the term "energy landscape" could be created by combining existing terms. However the philosophy of the approach was seen as a useful means through which changes in energy demand, sourcing and supply could be discussed in broad terms for a specific area. The stakeholders were able to engage with issues, typically only considered at a national or international level, in the context of a landscape that they understood. Different groups of stakeholders saw benefits of the approach, for example local planners valued the development of "independent" integrative tools, whilst local action groups agreed that it should ensure that their goals were recognized whilst illuminating other issues that they had not considered. proved insightful in more ways than we had initially intended. One clear strength of the questionnaire 
is that it brings all types of habitat and ecosystem service to the stakeholders' attention. The example of the stakeholder whose results are presented in Table 4 suggests that on balance he/she is more likely to support biomass (a positive aggregate score) in Marston Vale rather than wind (aggregate negative). However, the information presented back to the stakeholder gives them an opportunity to question their own values and judgments and discuss them with others. In particular, it identifies which parts of landscapes are more valued (e.g. woodlands) and which less (e.g. built up). The results are indicative not definitive and as the methodology is relatively simple (see [30]) it allows stakeholders to both recognize and adjust their position and enter dialogue with others about the specific areas they have concerns over.

Until the energyscapes term is more commonly used, the feeling was that a longer description may help gain its acceptance and use of additional phrases such as 'the local energy landscape' might be beneficial. It is informative to note that the term ecosystem services is still not widely used at a local level, despite being well known in academia and national policy circles.

\section{Conclusion}

Energyscapes is a valuable term to engage people in discussion about how the energy system interacts with their local environment and the other ecosystem services that it provides. It sets the specific components of the energy system in context of local energy demands and with other parts of the energy system, and offers a mechanism for making decisions that are more transparent and equitable; we hope that it can make a useful contribution to a wider public debate on our energy futures. In the same way that 'carbon footprint' or 'food miles' have become well-known terms that are widely (if loosely) used in and by the public, we hope that one day people will have a popular term to refer to the main local characteristics of energy demand, transport and supply. We propose that people discussing local wind farms or local authority development plans may start with the phrase 'our energyscape is...'.

\section{Acknowledgements}


361 The research described was funded by a Natural Environment Research Council (NERC) grant

362 (reference NE/H010432/1) awarded after a sandpit event in June 2009. The group wishes to express

363 their thanks to those who have commented and made positive suggestions about the work and all the

364 stakeholders, colleagues and students who have assisted in the process.

\section{$365 \quad 7 . \quad$ References}

366 [1] Mann ME, Bradley RS, Hughes MK. Northern hemisphere temperatures during the past 367 millennium: Inferences, uncertainties, and limitations. Geophys Res Lett 1999;26(6):759-62.

368 [2] Mann ME. Defining dangerous anthropogenic interference. Proc Natl Acad Sci U S A $369 \quad 2009 ; 106(11): 4065-66$.

370 [3] Ehrlich PR, Ehrlich A. Extinction: The Causes and Consequences of the Disappearance of $371 \quad$ Species. New York: Random House; 1981.

372 [4] Ehrlich PR, Mooney HA. Extinction, substitution, and ecosystem services. BioScience $1983 ; 33$ (4):248-54.

[7] Energy White Paper: Our energy future - creating a low carbon economy. UK Department of Transport and Department for the Environment, Food and Rural Affairs. London: HMSO;

[5] Costanza R, dArge R, deGroot R, Farber S, Grasso M, Hannon B, et al. The value of the world's ecosystem services and natural capital. Nature 1997;387 (6630):253-60. 2003, p. 139.

[8] Omer AM. Energy use and environmental impacts: A general review. Journal of Renewable and Sustainable Energy [Internet] 2009;1(5) [cited 2012 Mar 30] Available from: http://jrse.aip.org/ DOI: 10.1063/1.3220701 
[9] Pepermans G, Driesenb J, Haeseldonckxc D, Belmansc R, D’haeseleer W. Distributed generation: definition, benefits and issues. Energy Policy 2005;33 (6):787-98.

[10] Coleby AM, van der Horst D, Hubacek K, Goodier C, Burgess PJ, Graves A, et al. Environmental Impact Assessment and Ecosystems Services: the case of energy crops in England Journal of Environmental Planning and Assessment 2012; 55 (3):369-85.

[11] Carbon Trust. Small-scale wind energy - Policy insights and practical guidance. London, UK: Carbon Trust; 2008.

[12] Abou El-Ela AA, Allam SM, Shatla MM. Maximal optimal benefits of distributed generation using genetic algorithms. Electric Power Systems Research 2010;80 (7):869-77.

[13] Ren HB, Gao WJ. A MILP model for integrated plan and evaluation of distributed energy systems. Applied Energy 2010;87 (3):1001-14.

[14] Alarcon-Rodriguez A, Ault G, Galloway S. Multi-objective planning of distributed energy resources: A review of the state-of-the-art. Renewable \& Sustainable Energy Reviews 2010;14 (5):1353-66.

[15] Alanne K, Saari A. Distributed energy generation and sustainable development. Renewable and Sustainable Energy Reviews 2006;10 (6):539-58.

[16] Haughton AJ, Bond AJ, Lovett AA, Dockerty T, Sunnenberg G, Clark SJ, et al. A novel, integrated approach to assessing social, economic and environmental implications of changing rural land-use: a case study of perennial biomass crops. J Appl Ecol 2009;46 (2):315-22.

[17] Dicorato M, Fortea G, Trovato M. Environmental-constrained energy planning using energyefficiency and distributed-generation facilities. Renewable Energy 2008;33 (6):1297-1313.

[18] Hillier J, Whittaker C, Dailey G, Aylott M, Casella E, Richter GM, et al. Greenhouse gas emissions from four bioenergy crops in England and Wales: Integrating spatial estimates of yield and soil carbon balance in life cycle analyses. Glob Change Biol Bioenergy 2009;1(4):267-81. 
[19] Firbank LG, Barr CJ, Bunce RGH, Furse MT, Haines-Young R, Hornung M, et al. Assessing stock and change in land cover and biodiversity in GB: an introduction to Countryside Survey 2000. J Environ Manage 2003;67 (3):207-18.

[20] Fishbone LG, Hill D, Sailor VL. MARKAL, a multiperiod linear-programming model for energy-systems analysis applied to the United-States. Bulletin of the American Physical Society 1980;25 (4):494-95.

[21] Strachan N, Balta-Ozkan N, Joffe D, McGeevor K, Hughes N. Soft-linking energy systems and GIS models to investigate spatial hydrogen infrastructure development in a low-carbon UK energy system. Int J Hydrogen Energy 2009;34 (2):642-57.

[22] Howard D, Jay B, Whitaker J, Talbot J, Hughes N, Winskel M. Not just climate change: other social and environmental perspectives. In: Skea J, Ekins P, Winskel M, editors. Energy 2050: Making the transition to a secure low carbon energy system for the UK. London: Earthscan; 2010, p. 294-323.

[23] Heathwaite L. Sustainable Use of Natural Resources Theme Action Plan Swindon: Natural Environment Research Council; 2008, p. 11.

[24] de Vos R. EnergyScape. National Institute of Water \& Atmospheric Research, ; 2007.

[25] Angus A, Burgess PJ, Morris J, Lingard J. Agriculture and land use: Demand for and supply of agricultural commodities, characteristics of the farming and food industries, and implications for land use in the UK. Land Use Policy 2009;26 :S230-42.

[26] Burgess PJ, Casado MR, Gavu J, Mead A, Cockerill T, Lord R, et al. A framework for reviewing the trade-offs between, renewable energy, food, feed and wood production at a local level. Renewable \& Sustainable Energy Reviews 2012;16 (1):129-42.

[27] ESRI. www.esri.com. Redlands, California. 
[28] Armitage E, Badmos B, Barber C, Boye A, Brown P, Corney Riera A, et al. EnergyScapes and Ecosystem Services of the Marston vale. MSc Land Management and Geographical Information Management Group project. Cranfield: Cranfield University; 2010, p. 285.

[29] Biodiversity: the UK Action Plan. Department of the Environment London: HMSO; 1994,

[30] Wadsworth R, Wadsworth W, Hubacek K, Butler SJ, Burgess P, Gan G, et al. Ecosystem Services to assess Land Management Options: A method to capture diversity and consistency of stakeholder views? J Environ Manage Forthcoming 2012.

[31] Jackson DL. Guidance on the interpretation of the Biodiversity Broad Habitat Classification (terrestrial and freshwater types): Definitions and the relationships with other Habitat classifications. Peterborough: Joint Nature Conservation Committee; 2000.

[32] Millennium Ecosystem Assessment. Ecosystems and Human Well - Being: Synthesis. Washington, DC: Island Press; 2005.

[33] de Groot R. Function-analysis and valuation as a tool to assess land use conflicts in planning for sustainable, multi-functional landscapes. Landsc Urban Plan 2006;75 (3-4):175-86.

[34] de Groot RS, Wilson MA, Boumans RMJ. A typology for the classification, description and valuation of ecosystem functions, goods and services. Ecol Econ 2002;41 (3):393-408.

[35] Costanza R. Ecosystem services: Multiple classification systems are needed. Biol Conserv 2008;141(2):350-2.

[36] Berners-Lee M, Howard DC, Moss J, Kaivanto K, Scott WA. Greenhouse gas footprinting for small businesses — The use of input-output data. Sci Total Environ 2011; 409 (5) 883-91. 
Table 1 Options for the definition of an energyscape

455

456

457

458

Table 2A hierarchical list of components of the energy system used to check options for a location. It can be expanded in both directions adding further components (rows) or breaking the existing components into more detail (columns).

Table 3 Table of questions given to stakeholders to ask how they value different ecosystem services. All questions are asked for every habitat present, with the term habitat in the question being replaced by specific names (e.g. Improved grassland). Only the Broad Habitats commonly found in Marston Vale were used in this instance

Table 4 Summary responses from an individual stakeholder who was asked to score the impact of two new energy sources (wind and biomass) on the provision of the individual ecosystem services listed in Table $3(+2,+1,0,-1$, or -2$)$ within seven habitats commonly found in the study area. The responses are summed and grouped by ecosystem service category. 
Figure 4 Modeled land use in the Marston Vale in 2009 (from [26])

475 Figure 5 Modeled estimates of the intensity of demand for energy in the Marston Vale

Figure 1 Broad Habitats in Marston Vale from the satellite derived Land Cover Map 2007. Categories Arable \& horticultural (Au, Ba), Coniferous and Deciduous woodland (C, D, Fd), Agricultural and amenity grasslands (Gi) semi-natural grasslands, heaths and scrub (Gr, H, Hga, M, Sc), Urban and industrial (U, Ud, Ui, Us) Rivers, lakes and ponds (Wl)

Figure 2 A diagrammatic representation of the spatial domain of an energyscape as an open system with flows to other (energy) systems. The broken line indicates the energyscape boundary

Figure 3 Categories of ecosystem services drawn from [32], [33], [34] and [35]

476 Figure 6 Energy flow through elements of an energyscape 
an energyscape is

a spatial and temporal representation of a landscape

a spatial domain defined from an energy perspective

a framework

a functional unit

a description of the relationships between spatial patterns and man's energy system

a whole system model

that

describes the interactions between energy system components and other ecosystem services

visualizes the capture, conversion, transmission, use and disposal of energy relevant to human activities

emphasizes the capture, conversion, transmission, use and disposal of energy for human use

represents man's energy system and can be interrogated and manipulated to support the delivery of sustainable development

tells you how much land could/should be devoted to energy and at what cost

integrates all the processes related to man's use of energy 


\begin{tabular}{|c|c|c|}
\hline \multirow[t]{3}{*}{ Energy Sources } & Fossil fuels & $\begin{array}{l}\text { Coal } \\
\text { Oil } \\
\text { Gas } \\
\text { Peat }\end{array}$ \\
\hline & Nuclear & $\begin{array}{l}\text { Fission } \\
\text { Fusion }\end{array}$ \\
\hline & Renewables & $\begin{array}{l}\text { Wind } \\
\text { Bioenergy } \\
\text { Solar photovoltaic } \\
\text { Solar thermal } \\
\text { Hydro } \\
\text { Heat pumps } \\
\text { Wave \& tidal } \\
\text { Geothermal } \\
\text { Landfill gas } \\
\text { Waste }\end{array}$ \\
\hline \multirow[t]{5}{*}{ Energy Transport \& Storage } & Electricity & $\begin{array}{l}\text { Cable } \\
\text { Battery } \\
\end{array}$ \\
\hline & Gas & $\begin{array}{l}\text { Pipeline } \\
\text { Tanks }\end{array}$ \\
\hline & Liquid fuel & $\begin{array}{l}\text { Pipeline } \\
\text { Road \& rail transport } \\
\text { Tanks }\end{array}$ \\
\hline & Solid fuel & $\begin{array}{l}\text { Road \& rail transport } \\
\text { Storage bunkers }\end{array}$ \\
\hline & Heat & $\begin{array}{l}\text { Pipe } \\
\text { Water storage }\end{array}$ \\
\hline \multirow[t]{4}{*}{ Energy Demand Management } & Heat & Household insulation \\
\hline & Power & $\begin{array}{l}\text { Efficient equipment } \\
\text { Standby systems }\end{array}$ \\
\hline & Motion & $\begin{array}{l}\text { Car sharing } \\
\text { Speed restriction }\end{array}$ \\
\hline & Light & $\begin{array}{l}\text { LED } \\
\text { Natural light }\end{array}$ \\
\hline
\end{tabular}




\begin{tabular}{|c|c|}
\hline Cultural services & Does the habitat make you think ... \\
\hline Aesthetic & ... it is beautiful? \\
\hline Heritage & ... about the past? \\
\hline Jobs & ... of opportunities for employment? \\
\hline Recreation & ... you want to spend more time here? \\
\hline Scientific \& educational & ... there is a chance to learn or observe something interesting? \\
\hline Spiritual & ... about the future? \\
\hline Habitat services & Is the habitat where you would expect to see.... \\
\hline Flora & ... wild plants \\
\hline Fauna & ... wild animals \\
\hline Provisioning services & What do you get from the habitat... \\
\hline Fiber & ... fiber such as wood, flax or wool? \\
\hline Food & ... food for people or livestock? \\
\hline Freshwater & ... freshwater e.g. springs? \\
\hline Fuel & ... fuel e.g. firewood or biodiesel? \\
\hline Genetic & ... a genetic resource for the future? \\
\hline Medicinal/ornamental & ... Medicinal or ornamental plants? \\
\hline Regulating services & Does the habitat help ... \\
\hline Air quality & ... improve the air we breathe e.g. dust, smells, ammonium? \\
\hline Assimilation of carbon & ... lock up carbon from the atmosphere in the soil or plants? \\
\hline Buffer - chemicals & ... e.g. reduce pollution from acid rain, nutrients or pesticides? \\
\hline Buffer - physical & ... e.g. reduce erosion or flooding? \\
\hline Buffer - economic & ... e.g. "safe" jobs in times of recession? \\
\hline Climate & ... moderate the local (or global) climate? \\
\hline $\begin{array}{l}\text { Disease, pests \& natural } \\
\text { hazards }\end{array}$ & $\begin{array}{l}\text {... reduce the impact of pest and diseases, e.g., aphids, Lymes } \\
\text { disease, etc.? }\end{array}$ \\
\hline Erosion & ... prevent erosion? \\
\hline Fire & ... prevent wildfires? \\
\hline Pollination & ... provide nectar resources for bees and other pollinators. \\
\hline Water flow & ... moderate water flows (quantity) e.g. floods and droughts? \\
\hline Water quality & ... improve water quality? \\
\hline Supporting services & Does the habitat help support other services by ... \\
\hline Nutrient cycling & ... reducing nitrogen and phosphorus losses? \\
\hline Primary productivity & ... growing vegetation? \\
\hline Soil formation & ... encouraging soil formation? \\
\hline Hydrological cycling & ... circulating water around the environment? \\
\hline
\end{tabular}




\begin{tabular}{|c|c|c|c|c|c|c|c|c|}
\hline \multirow[b]{2}{*}{$\begin{array}{l}\text { Energy } \\
\text { Source }\end{array}$} & \multirow[b]{2}{*}{$\begin{array}{l}\text { Ecosystem Service } \\
\text { Group }\end{array}$} & \multicolumn{7}{|c|}{ Broad Habitat } \\
\hline & & $\begin{array}{c}\text { Arable \& } \\
\text { horticultural }\end{array}$ & $\begin{array}{l}\text { Boundary \& } \\
\text { linear features }\end{array}$ & $\begin{array}{l}\text { Broadleaved, } \\
\text { mixed \& } \\
\text { yew woodland }\end{array}$ & $\begin{array}{l}\text { Improved } \\
\text { grassland }\end{array}$ & $\begin{array}{l}\text { Rivers \& } \\
\text { streams }\end{array}$ & $\begin{array}{l}\text { Standing open } \\
\text { water \& canals }\end{array}$ & $\begin{array}{l}\text { Urban \& } \\
\text { built-up }\end{array}$ \\
\hline \multirow[t]{5}{*}{ Wind } & Cultural & 0 & -4 & -3 & 0 & 0 & 0 & 1 \\
\hline & Provisioning & 0 & 0 & -4 & 0 & 0 & 0 & 0 \\
\hline & Regulating & -1 & 0 & -13 & 0 & 0 & 0 & 2 \\
\hline & Supporting & 0 & 0 & 0 & 0 & 0 & 0 & 0 \\
\hline & Total & -1 & -4 & -20 & 0 & 0 & 0 & 3 \\
\hline \multirow[t]{5}{*}{ Biomass } & Cultural & -1 & -6 & -2 & 0 & 0 & 0 & 4 \\
\hline & Provisioning & -1 & 0 & 3 & -1 & 0 & 0 & 0 \\
\hline & Regulating & 1 & 0 & 0 & -2 & 0 & 0 & 0 \\
\hline & Supporting & 3 & 0 & 0 & 4 & 0 & 0 & 0 \\
\hline & Total & 2 & -6 & 1 & 1 & 0 & 0 & 4 \\
\hline
\end{tabular}




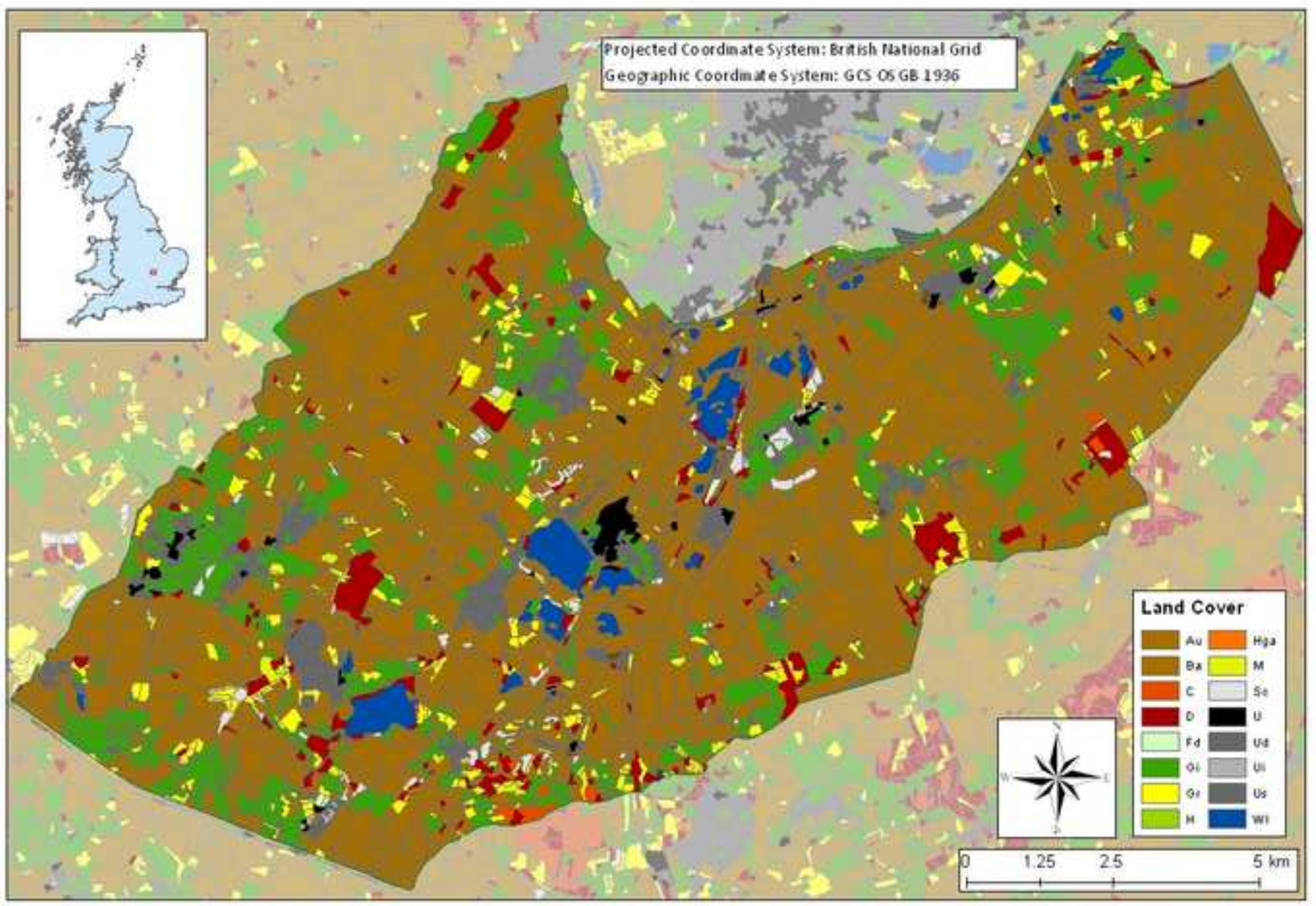




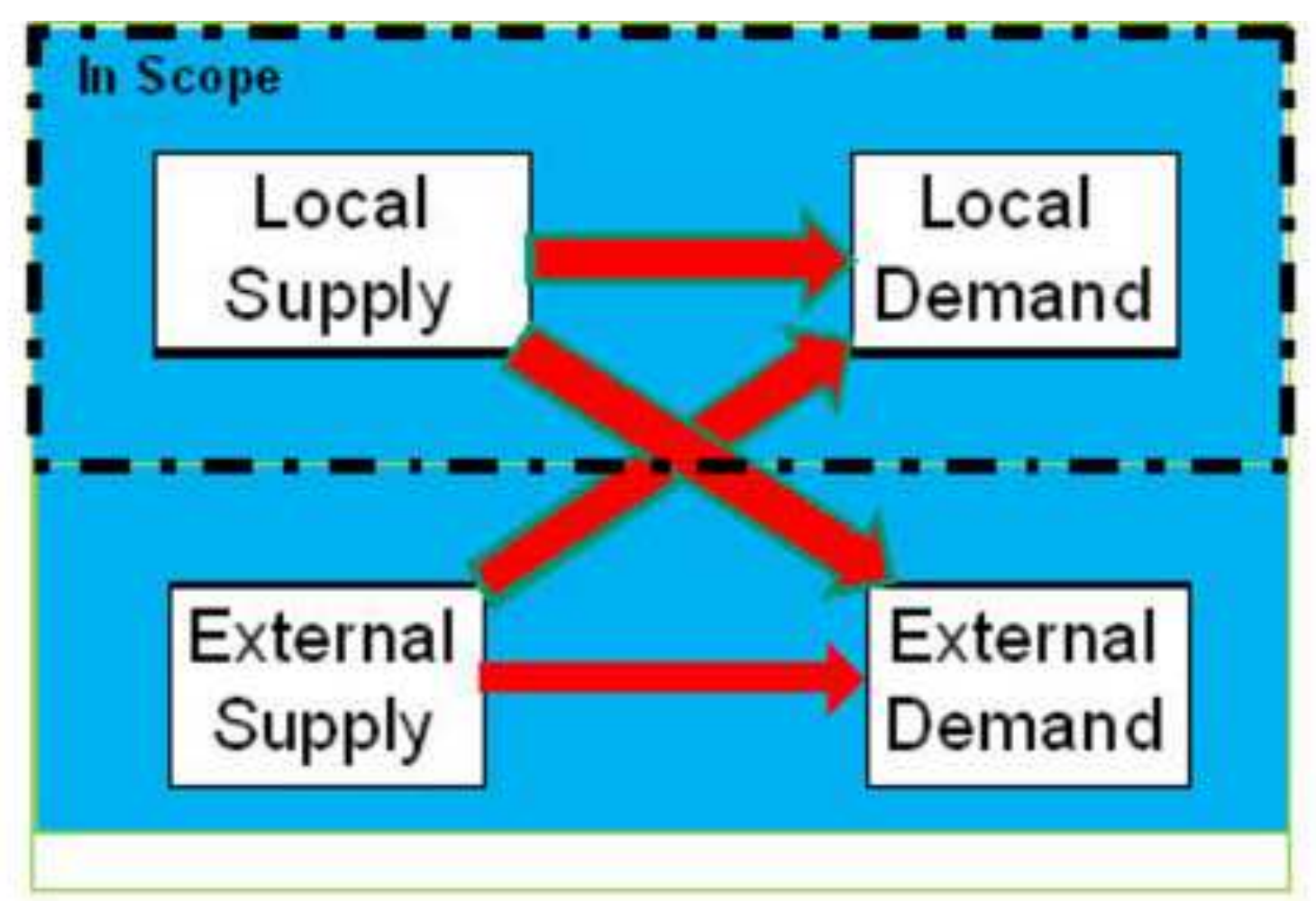




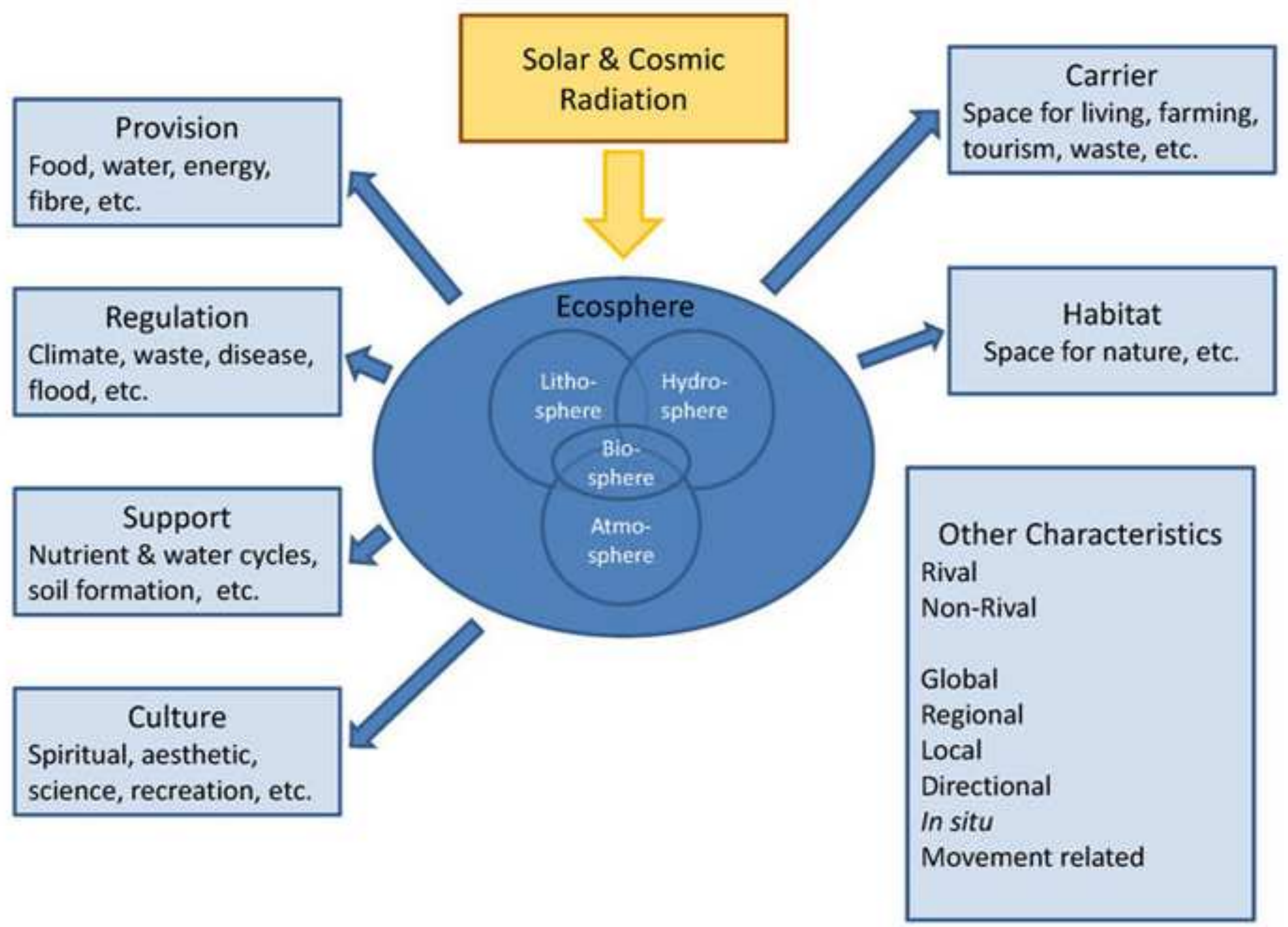


Click here to download high resolution image

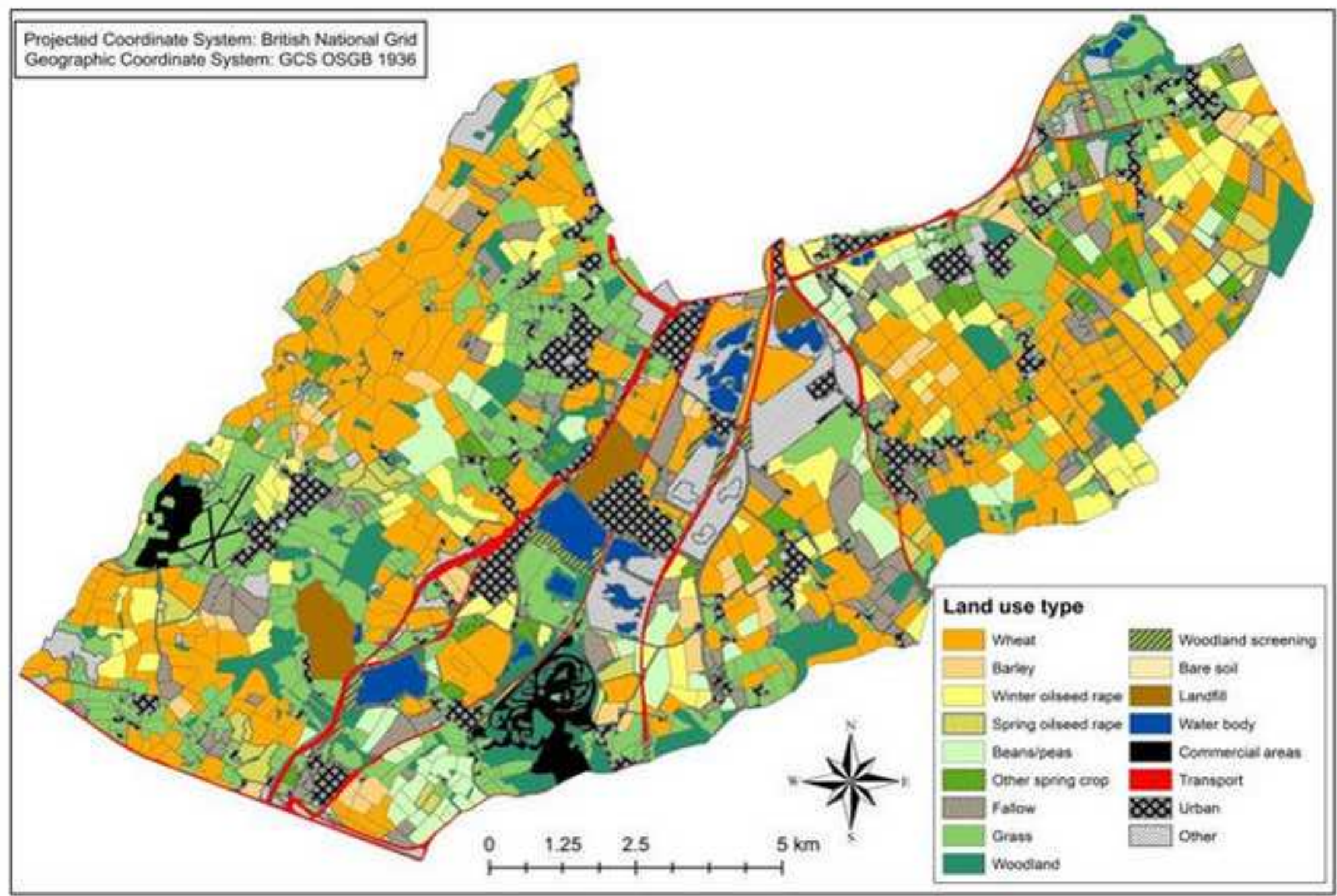




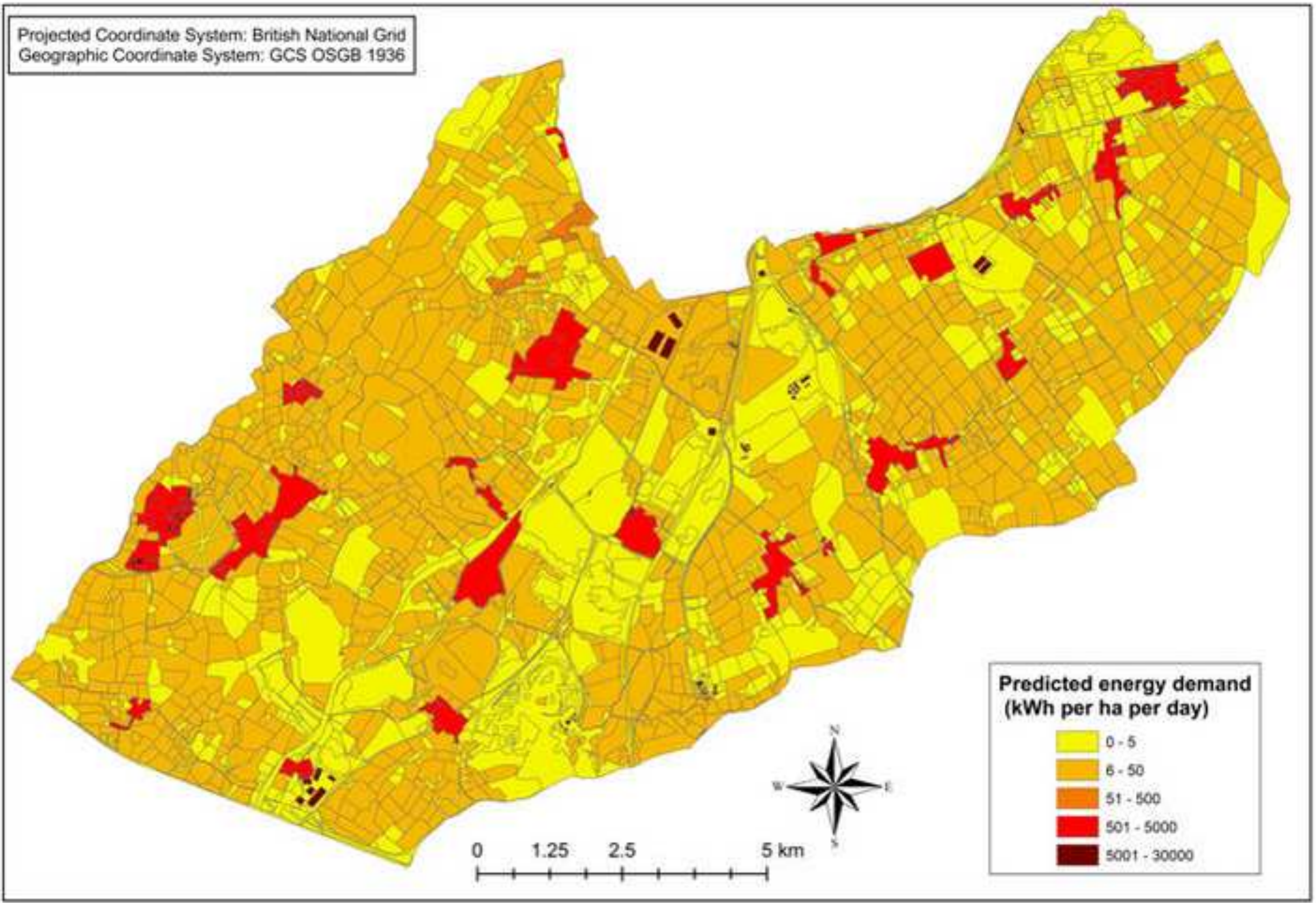




\section{Recursive representation}
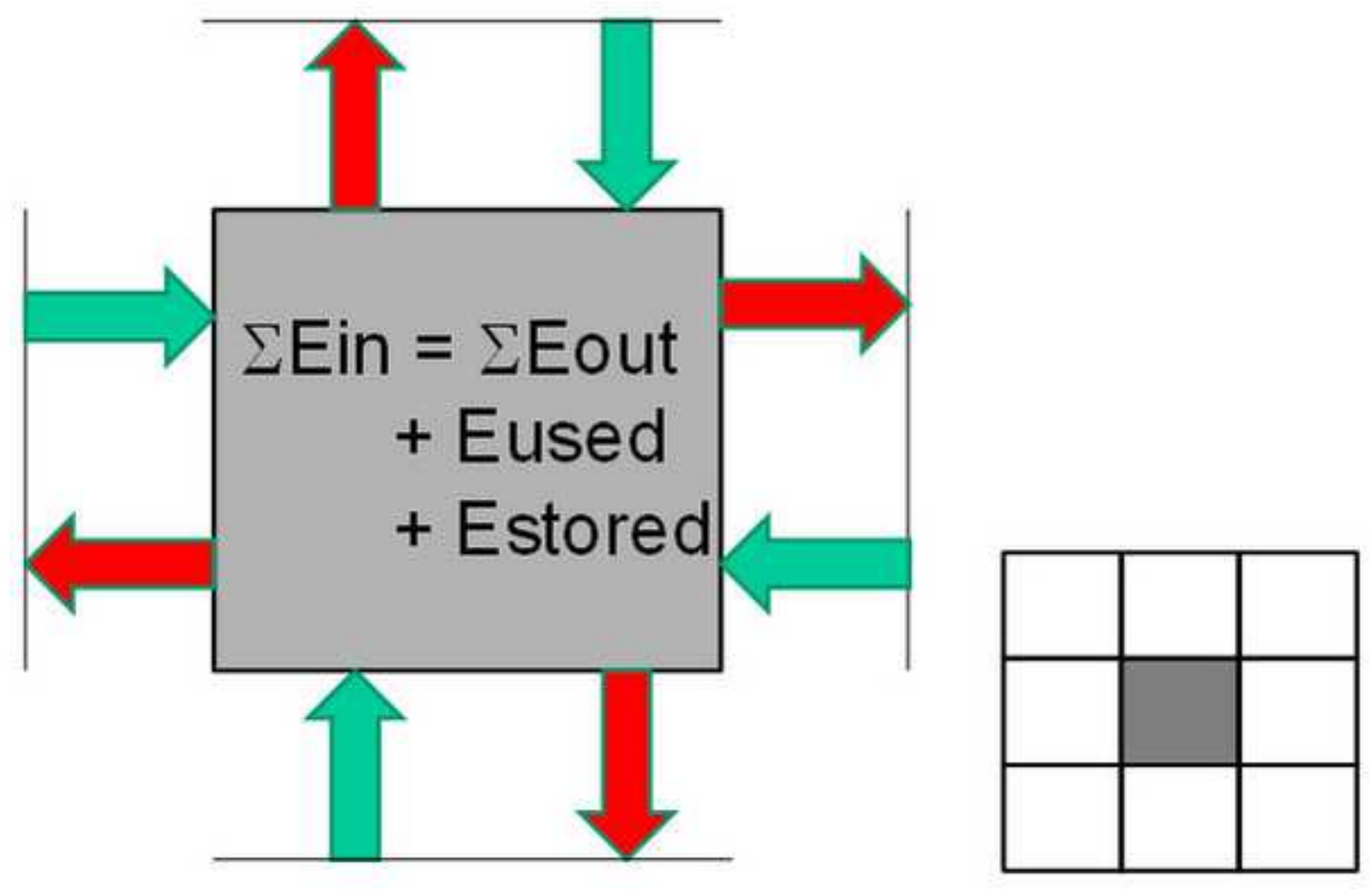